\title{
Three cases of systemic amyloidosis successfully diagnosed by subcutaneous fat tissue biopsy of the hip
}

This article was published in the following Dove Press journal:

Clinical Interventions in Aging

5 August 2016

Number of times this article has been viewed

\section{Masahisa Arahata' \\ Shigeru Shimadoi' \\ Satosi Yamatani' \\ Shin-ichi Hayashi ${ }^{2}$ \\ Shigeharu Miwa ${ }^{2}$ \\ Hidesaku Asakura ${ }^{3}$ \\ Shinji Nakao ${ }^{4}$}

'Department of Internal Medicine, Nanto Municipal Hospital, Nanto,

${ }^{2}$ Department of Diagnostic Pathology, Graduate School of Medicine and

Pharmaceutical Sciences, University of Toyama, Toyama, ${ }^{3}$ Department of Internal Medicine (III), ${ }^{4}$ Department of Cellular Transplantation Biology,

Division of Cancer Medicine,

Graduate School of Medical Science, Kanazawa University, Kanazawa, Japan
Correspondence: Masahisa Arahata Department of Internal Medicine, Nanto Municipal Hospital, 938 Inami, Nanto,

Toyama 932-021I, Japan

Tel +8I $76382 \quad 1475$

Fax $+8 \mid 76382$ I853

Email rqxhf297@yahoo.co.jp

\begin{abstract}
Fine-needle aspiration biopsy of the abdominal fat pad is considered to be a minimally invasive procedure for diagnosing systemic amyloidosis. However, this procedure is sometimes difficult and can be dangerous for elderly patients whose abdominal fat layer is thin because of malnutrition. In such cases, alternative diagnostic methods are required. We report three elderly patients with heart failure complicated by malnutrition. In all cases, electrocardiogram showed low voltage in the limb leads and a pseudoinfarct pattern in the chest leads, and echocardiography showed left ventricular wall thickening with granular sparkling appearance. These patients were suspected of having amyloid cardiomyopathy but could not undergo myocardial biopsies because of their poor conditions. After failed attempts at biopsy of the abdominal fat pad or the other organs, subcutaneous fat tissue biopsy over the hip led to the diagnosis of systemic amyloidosis with cardiomyopathy. The resultant diagnosis guided us to choose the appropriate treatment for the patients. This article illustrates that subcutaneous fat tissue biopsy of the hip could be a useful procedure for diagnosing systemic amyloidosis in elderly patients, particularly when a fat tissue biopsy of the abdomen is associated with a high risk of complications because of malnutrition.
\end{abstract}

Keywords: systemic amyloidosis, amyloid cardiomyopathy, fine-needle aspiration biopsy, subcutaneous fat tissue, hip, abdominal fat pad

\section{Introduction}

The diagnosis of systemic amyloidosis (SA) requires tissue biopsies from affected organs, owing to a lack of specific disease markers. Fine-needle aspiration biopsy (FNAB) of the abdominal fat pad (AFP) is reported to be a minimally invasive, highly reliable screening method for the diagnosis of SA. ${ }^{1-10}$ However, this procedure has not been standardized and requires skill to ensure precise sampling. ${ }^{4}$ Moreover, this procedure may be less successful than previously reported, because of variation in practice setting, experience level, or diagnostic technique. ${ }^{11}$ Additionally, abdominal wall centesis can be dangerous in elderly patients; these patients may present with a thin AFP owing to malnutrition or may have difficulties remaining at rest because of cognitive impairment. Although new devices and techniques have been developed to increase the certainty of revealing amyloid deposits, ${ }^{12,13}$ adipocytes are often difficult to aspirate by FNAB-AFP in malnourished, elderly patients, leading to an inability to make a diagnosis. In this study, we present three cases of SA that were diagnosed by subcutaneous fat tissue biopsy over the hip; all of these patients were ineligible for deep organ biopsy because of their poor condition and because they had failed to be diagnosed by conventional FNAB of the AFP. Written informed consent was obtained 
from the patients or the next of kin for publication of this report and any accompanying images.

\section{Case report I}

Case 1, a 76-year-old female with decompensated chronic heart failure (CHF), was admitted to our hospital in October 2011. Her CHF did not respond to medical therapy and her general condition continued to deteriorate. An electrocardiogram showed low voltage in the limb leads and low R-wave progression, compatible with pseudoinfarct pattern, in the chest leads V1-V3 (Figure 1). Echocardiography showed increased left ventricular wall thickness (Figure 2) with granular sparkling appearance (Figure 2A and B). Blood chemistry examination revealed $\mathrm{M}$ proteins derived from immunoglobulin (Ig) G lambda light chain, but no abnormalities in IgG levels (Table 1). Based on these findings, amyloid cardiomyopathy due to amyloid light chain amyloidosis was strongly suspected as a cause of her CHF. To obtain histological evidence of amyloid light chain amyloidosis, bone marrow and gastric mucosa were biopsied, but both specimens failed to show amyloid deposition. However, amyloid deposits were revealed in the subcutaneous fat tissue (Figure 3) that was biopsied incidentally with the bone marrow tissue from her posterior iliac crest (Figure $3 \mathrm{~A}-\mathrm{C}$ ). The percentage of plasma cells in the bone marrow (14.8\% of all nucleated cells) was slightly increased but did not fulfill the criteria for symptomatic multiple myeloma. These findings allowed us to make a diagnosis of SA with cardiomyopathy, but we could not determine the type of SA because there was no biased staining of lambda light chain in the fat tissue. The patient was treated with oral melphalan and dexamethasone to ameliorate $\mathrm{M}$ proteinemia without apparent effects, and she died of CHF 2 months after the diagnosis.

\section{Case report 2}

Case 2, a 91-year-old female with a 6-month history of progressive chronic kidney disease and $\mathrm{CHF}$, presented with anorexia and malnutrition in January 2015. Her serum was positive for IgG-lambda M proteins, with a decrease in the free light chain kappa/lambda ratio (Table 1). Blood tests, electrocardiogram, and echocardiography showed characteristics of amyloid cardiomyopathy, similar to those seen in Case 1 (Table 1; Figures 1B, 2C, and 2D). The patient also had comorbidities such as anemia, proteinuria associated with chronic kidney disease, sclerotic skin lesions, dysautonomia, and progressive muscle weakness. She was suspected to have SA and underwent the FNAB-AFP procedure, but no adipocytes could be aspirated because of malnutrition. Based on the experience gained with Case 1, we suspected that subcutaneous fat tissue aspiration from the hip might be useful for diagnosing SA. A specimen aspirated from the left posterior iliac crest contained adipocytes and amyloid deposits were evident in the subcutaneous fat tissue (Figure 3D-F). However, the presence of ALs could not be confirmed because the specimen was too small to analyze with immunohistochemical staining. The patient was eventually diagnosed with SA complicated by cardiomyopathy. Bone marrow biopsy was not performed because no specific
A

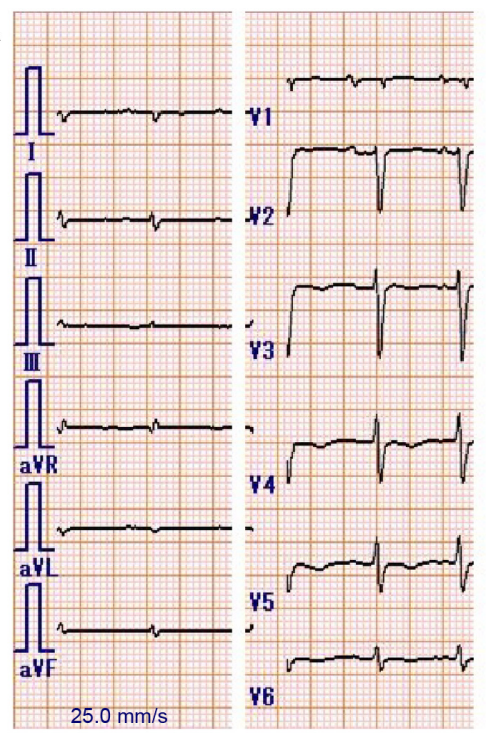

B

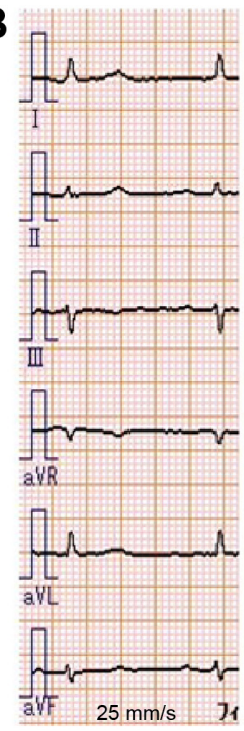

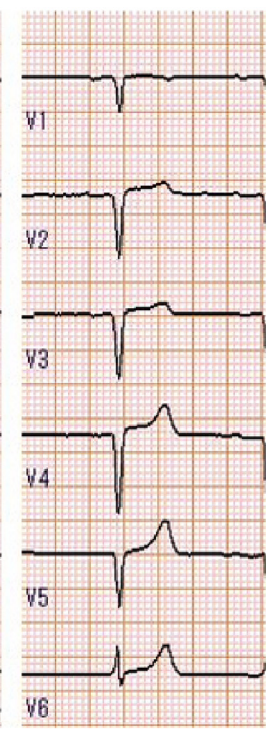
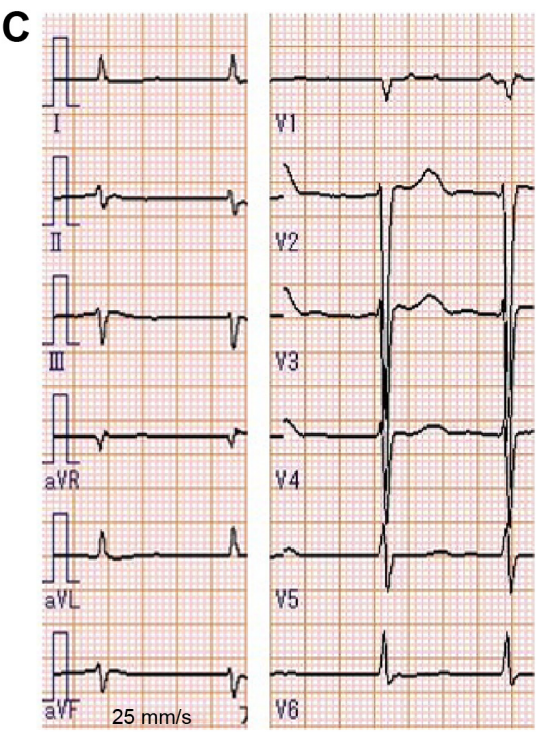

Figure I Electrocardiogram of the three presented cases.

Notes: In all cases, electrocardiogram showed low voltage in the limb leads. (A) Case I: low R-wave progression was seen in the chest leads VI to V3. (B) Case 2: the lack of R-wave was seen in the chest leads VI to V5. (C) Case 3: low R-wave progression was seen in the chest leads VI to V4, similar to Case I. These abnormal R-waves were considered a pseudoinfarct pattern. 

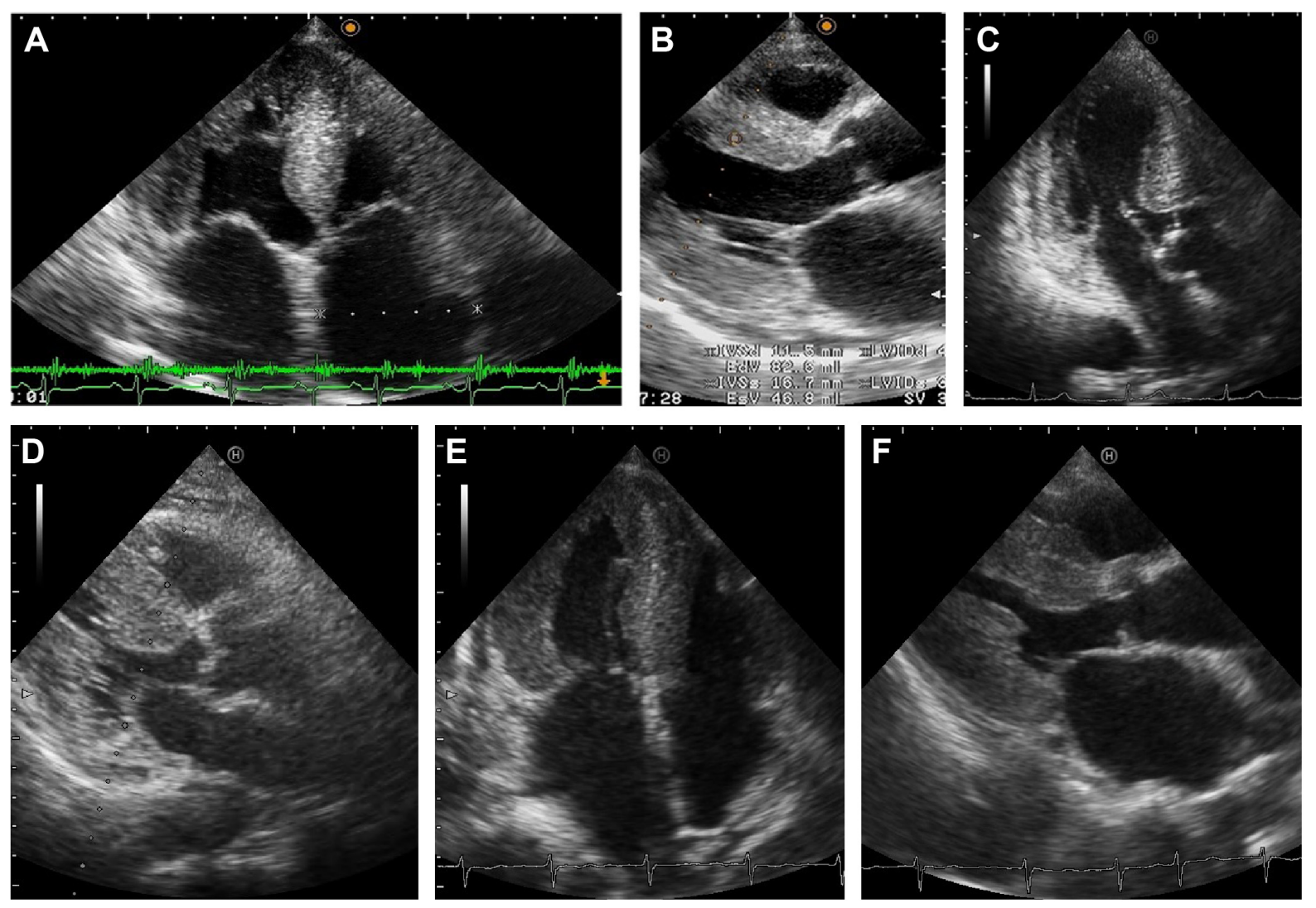

Figure 2 Echocardiography of the three presented cases.

Notes: Parasternal long-axis views (A, C, and E) and apical four-chamber views (B, D, and F) are presented. (A and B) Case I: granular sparkling appearance was seen in the interventricular septum (IVS), which was $11.5 \mathrm{~mm}$ in thickness. (C and D) Case 2: granular sparkling appearance was seen in the IVS and the lateral wall. The IVS of Case 2 was less thickened ( $9.8 \mathrm{~mm}$ in thickness), but the left ventricular wall exhibited diffuse hypertrophy with diastolic dysfunction (E/e' 15.55$)$ without valvular dysfunction. (E and F) Case 3: granular sparkling appearance was shown in the IVS and lateral wall, and the IVS was $13.0 \mathrm{~mm}$ in thickness.

Table I Laboratory data of the cases at diagnosis

\begin{tabular}{|c|c|c|c|c|}
\hline Variable & Normal range & Case I & Case 2 & Case 3 \\
\hline WBC $(/ \mu \mathrm{L})$ & $3,500-9,100$ & 3,580 & 5,270 & 8,020 \\
\hline Hemoglobin (g/dL) & $11.3-15.2$ & 13.2 & 9.2 & 15.3 \\
\hline Platelets $(/ \mu \mathrm{L})$ & $130,000-369,000$ & 135,000 & 359,000 & 146,000 \\
\hline Albumin (g/dL) & $4.0-5.0$ & 3.7 & 2.5 & 2.8 \\
\hline T-Cho (mg/dL) & $150-219$ & 130 & 112 & 153 \\
\hline Creatinine (mg/dL) & $0.47-0.79$ & 0.68 & 1.32 & 0.89 \\
\hline BNP $(p g / m L)$ & $0.0-18.4$ & 1,250 & $|4|$ & $\mathrm{I}, 820$ \\
\hline NT-proBNP (pg/mL) & $0-125$ & 6,389 & 4,217 & 78,120 \\
\hline Troponin T (ng/mL) & $0.000-0.014$ & 0.116 & 0.182 & 0.281 \\
\hline Transthyretin (mg/dL) & $22.0-40.0$ & 14.4 & 11.5 & 7.5 \\
\hline$\beta 2-M G(m g / L)$ & $1.0-1.9$ & 2.8 & 9.1 & 4.5 \\
\hline $\lg A(m g / d L)$ & $110-410$ & 60 & 127 & 312 \\
\hline $\lg M(\mathrm{mg} / \mathrm{dL})$ & $46-260$ & 93 & 63 & 82 \\
\hline $\operatorname{lgG}(\mathrm{mg} / \mathrm{dL})$ & $870-1,700$ & 1,609 & $\mathrm{I}, 564$ & 2,033 \\
\hline $\operatorname{lgD}(\mathrm{mg} / \mathrm{dL})$ & $0.0-9.0$ & $\leqq 0.6$ & 0.9 & $\leqq 0.6$ \\
\hline FLC-К (mg/L) & $3.3-19.4$ & NA & 66.9 & 55.6 \\
\hline $\mathrm{FLC}-\lambda(\mathrm{mg} / \mathrm{L})$ & $5.7-26.3$ & NA & 268.0 & 44.8 \\
\hline$\kappa / \lambda$ ratio & $0.26-1.65$ & NA & 0.25 & 1.24 \\
\hline M protein* & Negative & $\lg G-\lambda$ & $\lg G-\lambda$ & Negative \\
\hline
\end{tabular}

Note: *M protein was analyzed by serum immunoelectrophoresis and "negative" means that it was not detected with this method.

Abbreviations: $\beta 2-M G$, beta2-microglobulin; BNP, serum B-type natriuretic peptide; FLC, free light chain; $\gamma$-GTP, gamma-glutamyl transpeptidase; lg, immunoglobulin; LDH, lactate dehydrogenase; NA, not available; NT-proBNP, N-terminal pro-B-type natriuretic peptide; T-Cho, total cholesterol; WBC, white blood cells. 

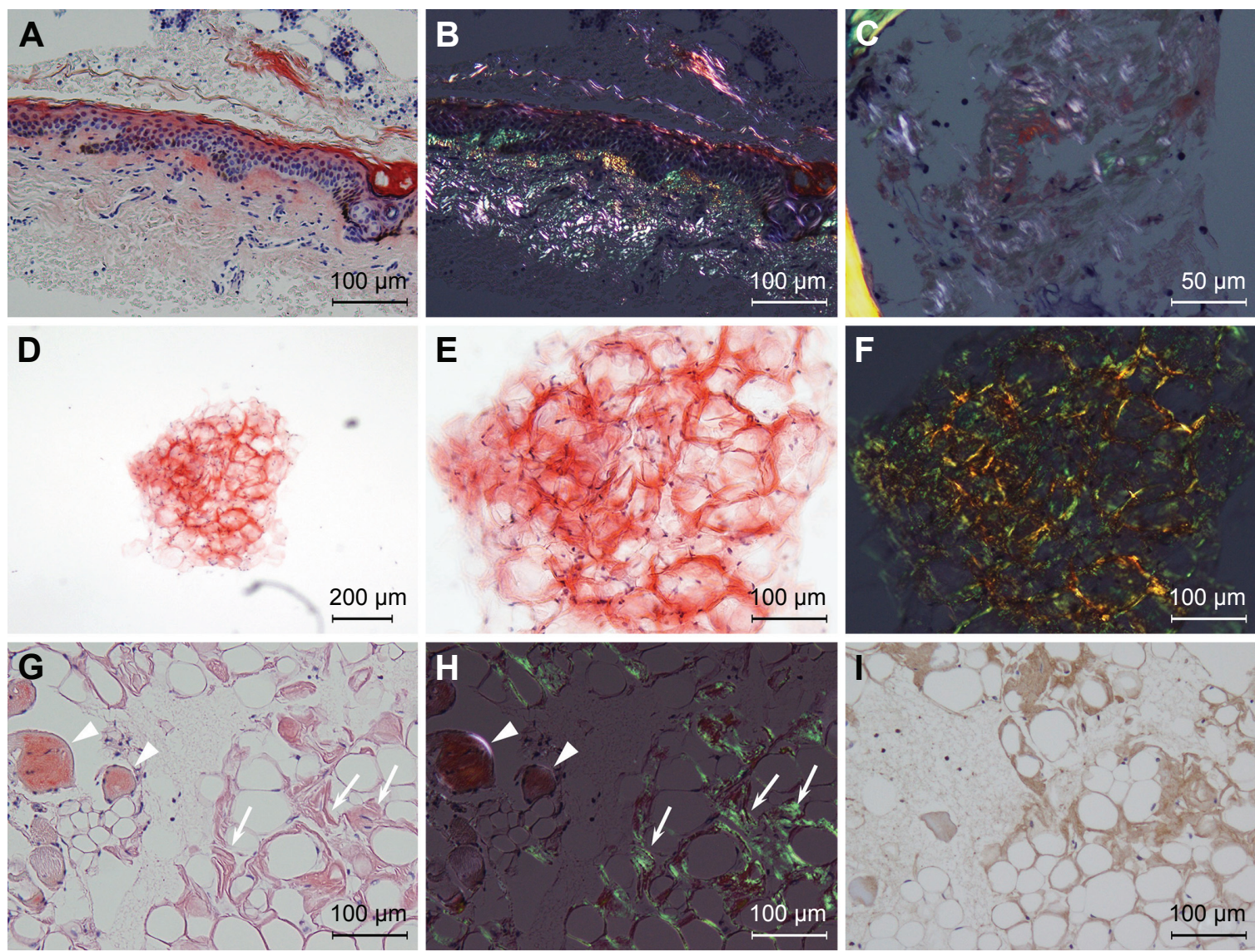

Figure 3 Light micrograph of the subcutaneous fat tissue.

Notes: (A-C) Case I: skin and subcutaneous fat tissue around the left posterior iliac crest was inadvertently biopsied with bone and bone marrow in Case I. Therefore, bone marrow tissue is seen in the upper right area of the figures ( $\mathbf{A}$ and $\mathbf{B}$ ). Patchy amyloid deposits in dermis are stained orange red with Congo red (A). Green birefringence of the amyloid deposits can be seen under polarized light but cannot be detected in bone marrow tissue (B). Slight green birefringence of amyloid deposits is also seen in subcutaneous fat tissue adjacent to the dermis under polarized light (C). (D-F) Case 2: we could obtain only one cluster of fatty tissue after repeated aspiration from the hip in Case 2 (D). The sample was too small to slice into biopsy sections. Interstitial tissue between the adipocytes is stained orange red with Congo-red stain (E), and green birefringence of the amyloid deposits can be seen under polarized light (F). (G-I) Case 3: subcutaneous fat tissue aspirated from the hip is patchily stained orange red with Congo red (white arrows; $\mathbf{G}$ ) and green birefringence of the patch can be seen under polarized light $(\mathbf{H})$. Muscular tissue is also stained with Congo red but it is not brilliant apple green under polarized light (arrow heads). Immunohistochemistry of the subcutaneous fat tissue shows that amyloid deposits can be stained with antitransthyretin antibody (I).

treatment was indicated even if she had been found to have multiple myeloma. Her anorexia improved with supportive care, including treatment for CHF.

\section{Case report 3}

Case 3, a 93-year-old female with a 10-year history of hypertension, presented with left hemiparalysis and was admitted to our hospital in September 2015. Diffusion-weighted magnetic resonance imaging revealed a widespread high-intensity lesion in the right middle cerebral artery area and electrocardiogram was compatible with paroxysmal atrial fibrillation. The patient was diagnosed with cardiogenic cerebral embolism and was treated with edaravone and heparin for 2 weeks. However, she gradually developed signs of heart failure, including whole body edema, pulmonary edema, massive pleural effusion, and anorexia. Based on echocardiogram findings similar to those seen in Cases 1 and 2, the patient was suspected to have SA (Table 1, Figures 1C, 2E, and 2F). We could not perform FNAB-AFP because her abdominal wall was too thin to apply centesis safely (Figure 4) and she could not remain still during the FNAB procedure because of stroke-induced cognitive impairment. Thus, we performed FNAB of subcutaneous fat tissue from the hip. Amyloid deposits in the fat tissue were revealed by Congo red staining with polarizing light exposure, as well as with transthyretin immunostaining (Figure $3 \mathrm{G}-\mathrm{I}$ ). The patient was diagnosed with senile SA and amyloid cardiomyopathy. The irreversible condition of her disease led us to provide supportive care instead of intensive treatment. The patient died of multiple organ failure, as a result of circulatory insufficiency, 7 days after the diagnosis. 


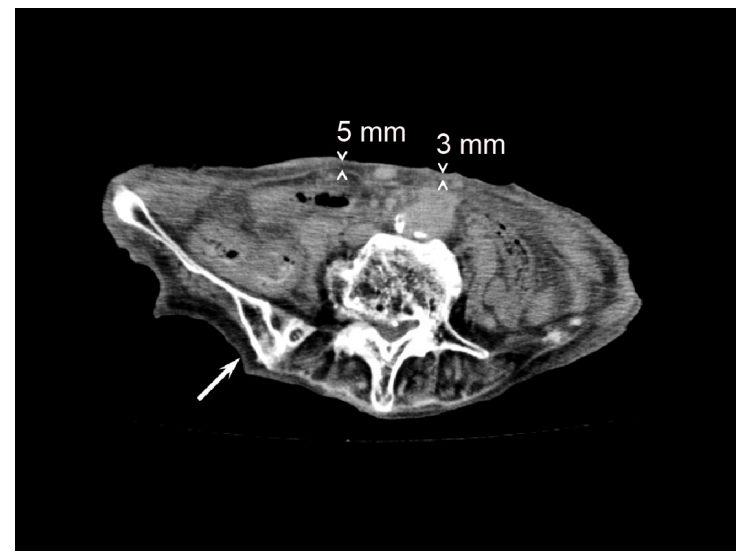

Figure 4 The abdominal computerized tomography of Case 3.

Notes: The abdominal wall around the navel was $\sim 3-5 \mathrm{~mm}$ in thickness, where FNAB-AFP is usually performed. The white arrow indicates where FNAB of the hip was performed.

Abbreviations: AFP, abdominal fat pad; FNAB, fine-needle aspiration biopsy.

\section{Discussion}

This report illustrates three cases of SA diagnosed by subcutaneous fat tissue biopsy of the hip. Two of these were diagnosed as SA by an FNAB from the posterior iliac crest. Although a previous study has suggested that a diagnosis of SA may not change the recommended treatment in many cases, a definitive diagnosis can be helpful in ruling out other underlying conditions as the cause of patients' symptoms. ${ }^{6}$ In Cases 2 and 3, the diagnosis of SA offered a poor prognosis, allowing us to select supportive care rather than intensive treatment. Making a definitive diagnosis of SA in Case 2 also helped us rule out other causes of CHF and choose appropriate care for the patient, which significantly relieved the patient's symptoms. The prognosis of Case 3 was considered to be more miserable because her heart failure was developed subsequent to many irreversible impairments such as stroke-induced dementia, hemiparalysis, aphasia, and severe dysphagia, which led to malnutrition. Owing to advanced dementia and malnutrition, her prognosis was estimated to be $<6$ months according to a guideline. ${ }^{14}$ In addition, the diagnosis of SA indicated that her heart failure needed maintenance therapies, but these impairments were thought to disturb continuous oral medication. Therefore, after diagnosis of SA, the patient was thought to be in the end-of-life and was provided palliative care for SA. ${ }^{15}$

According to current guidelines or experts' reviews, a diagnosis of SA requires the detection of amyloid deposits, which are then confirmed by Congo red staining with classical apple green birefringence under polarized light. ${ }^{16-20}$ FNABAFP is considered to be an excellent screening procedure for diagnosing $\mathrm{SA},{ }^{21}$ with a specificity of $92 \%-100 \% 0^{1-8}$ and is introduced as the simplest and least invasive procedure in many tissue biopsies. ${ }^{20}$ This diagnostic procedure has been established by dermatologists, surgeons, and pathologists. ${ }^{22}$ The choice of the anterior abdominal skin for the aspiration biopsy was based on a systematic study of the occurrence of amyloid $\mathrm{A}$ in the skin of different parts of the body. ${ }^{23}$ However, this study did not examine about the detection rate of amyloid deposits in the subcutaneous tissue of the hips. ${ }^{20}$ Most primary care physicians are not skilled in this procedure because the prevalence of SA is relatively low and physicians have few chances to carry out FNAB. On the other hand, centesis of the posterior iliac crest is often performed by physicians and hematologists to aspirate bone marrow and is recognized as a safe procedure that does not risk damaging deep organs. In this respect, FNAB of the subcutaneous tissue from the posterior iliac crest has some advantages over FNAB-AFP, especially in patients for whom FNAB-AFP is associated with considerable risks. To our knowledge, however, there has been no study that evaluated the usefulness of the subcutaneous fat tissue biopsy of the hip in diagnosing SA.

The sensitivity of detecting amyloid deposits in subcutaneous fat tissue through the AFP biopsy varies from one type of amyloidosis to another. It is higher in patients with amyloid light chain and amyloid A amyloidosis than in patients with senile SA. This is probably true for the subcutaneous fat tissue biopsy of the hip, but we do not have exact data regarding different types of amyloidosis. Further studies are required to clarify this issue.

In our three cases, SA could only be diagnosed by subcutaneous fat tissue of the hip because the poor conditions of the patients did not allow biopsies from other organs. These patients had no complication associated with the diagnostic procedures. Moreover, the resultant diagnosis of SA guided us to choose appropriate treatments for the patients.

\section{Conclusion}

Subcutaneous fat tissue biopsy of the hip was useful for diagnosing SA in elderly patients for whom FNAB-AFP failed to obtain sufficient material and biopsy of other organs was associated with a high risk of complications. These promising results warrant further clinical studies to clarify the usefulness of FNAB of the hip in the diagnosis of SA.

\section{Acknowledgments}

The authors wish to thank Hiroe Niwa and Kazumi Mukai, the cytotechnologists at the Department of Pathology 
Laboratory of Nanto Municipal Hospital, for their special works and efforts.

\section{Disclosure}

The authors report no conflicts of interest in this work.

\section{References}

1. Duston MA, Skinner M, Shirahama T, Cohen AS. Diagnosis of amyloidosis by abdominal fat aspiration. Analysis of four years' experience. Am J Med. 1987;82(3):412-414.

2. Gertz MA, Li CY, Shirahama T, Kyle RA. Utility of subcutaneous fat aspiration for the diagnosis of systemic amyloidosis (immunoglobulin light chain). Arch Intern Med. 1988;148(4):929-933.

3. Duston MA, Skinner M, Meenan RF, Cohen AS. Sensitivity, specificity, and predictive value of abdominal fat aspiration for the diagnosis of amyloidosis. Arthritis Rheum. 1989;32(1):82-85.

4. Masouye I. Diagnostic screening of systemic amyloidosis by abdominal fat aspiration: an analysis of 100 cases. Am J Dermatopathol. 1997;19(1): $41-45$.

5. Guy CD, Jones CK. Abdominal fat pad aspiration biopsy for tissue confirmation of systemic amyloidosis: specificity, positive predictive value, and diagnostic pitfalls. Diagn Cytopathol. 2001;24(3):181-185.

6. Ansari-Lari MA, Ali SZ. Fine-needle aspiration of abdominal fat pad for amyloid detection: a clinically useful test? Diagn Cytopathol. 2004; 30(3):178-181.

7. van Gameren II, Hazenberg BP, Bijzet J, van Rijswijk MH. Diagnostic accuracy of subcutaneous abdominal fat tissue aspiration for detecting systemic amyloidosis and its utility in clinical practice. Arthritis Rheum. 2006;54(6):2015-2021.

8. Dhingra S, Krishnani N, Kumari N, Pandey R. Evaluation of abdominal fat pad aspiration cytology and grading for detection in systemic amyloidosis. Acta Cytol. 2007;51(6):860-864.

9. Bogov B, Lubomirova M, Kiperova B. Biopsy of subcutaneus fatty tissue for diagnosis of systemic amyloidosis. Hippokratia. 2008;12(4): 236-239.
10. Miyazaki K, Kawai S, Suzuki K. Abdominal subcutaneous fat pad aspiration and bone marrow examination for the diagnosis of AL amyloidosis: the reliability of immunohistochemistry. Int J Hematol. 2015; 102(3):289-295.

11. Halloush RA, Lavrovskaya E, Mody DR, Lager D, Truong L. Diagnosis and typing of systemic amyloidosis: the role of abdominal fat pad fine needle aspiration biopsy. Cytojournal. 2009;6:24.

12. Kettwich LG, Sibbitt WL Jr, Emil NS, et al. New device technologies for subcutaneous fat biopsy. Amyloid. 2012;19(2):66-73.

13. Shidham VB, Hunt B, Jardeh SS, Barboi AC, Devata S, Hari P. Performing and processing FNA of anterior fat pad for amyloid. J Vis Exp. 2010; (44):e1747.

14. The National Hospice Organization. Medical guidelines for determining prognosis in selected non-cancer diseases. Hosp J. 1996;11(2): $47-63$.

15. Mitchell SL. Advanced dementia. N Engl J Med. 2015;372(26): 2533-2540.

16. Wechalekar AD, Gillmore JD, Hawkins PN. Systemic amyloidosis. Lancet. 2015. Epub 2015 Dec 21.

17. Gillmore JD, Wechalekar A, Bird J, et al. Guidelines on the diagnosis and investigation of AL amyloidosis. Br J Haematol. 2015;168(2): 207-218.

18. Rajkumar SV, Dimopoulos MA, Palumbo A, et al. International Myeloma Working Group updated criteria for the diagnosis of multiple myeloma. Lancet Oncol. 2014;15(12):e538-e548.

19. Ando Y, Coelho T, Berk JL, et al. Guideline of transthyretin-related hereditary amyloidosis for clinicians. Orphanet J Rare Dis. 2013;8:31.

20. Palladini G, Merlini G. Systemic amyloidosis: what an internist should know. Eur J Intern Med. 2013;24(8):729-739.

21. Westermark P. Subcutaneous adipose tissue biopsy for amyloid protein studies. Methods Mol Biol. 2012;849:363-371.

22. Westermark P. Amyloid diagnosis, subcutaneous adipose tissue, immunohistochemistry and mass spectrometry. Amyloid. 2011;18(4): 175-176.

23. Westermark P. Occurrence of amyloid deposits in the skin in secondary systemic amyloidosis. Acta Pathol Microbiol Scand A. 1972;80(6): 718-720.
Clinical Interventions in Aging

\section{Publish your work in this journal}

Clinical Interventions in Aging is an international, peer-reviewed journal focusing on evidence-based reports on the value or lack thereof of treatments intended to prevent or delay the onset of maladaptive correlates of aging in human beings. This journal is indexed on PubMed Central, MedLine,

\section{Dovepress}

CAS, Scopus and the Elsevier Bibliographic databases. The manuscript management system is completely online and includes a very quick and fair peer-review system, which is all easy to use. Visit http://www.dovepress. com/testimonials.php to read real quotes from published authors. 